\title{
Empreendedorismo local: uma análise a partir das características de clientes de pet shops
}

\author{
Local entrepreneurship: an analysis from \\ characteristics of clients of pet shops
}

\author{
Ivano Ribeiro ${ }^{1}$ \\ Filipe de Carvalho ${ }^{2}$ \\ Antônio Oliveira de Carvalho ${ }^{3}$ \\ Renato Fabiano Cintra ${ }^{4}$ \\ Fernando Antônio Ribeiro Serra ${ }^{5}$
}

\section{Resumo}

O mercado relacionado aos animais de estimação (pet) cresce de forma significativa no Brasil. Este segmento que cresceu a uma taxa 16,4\% de 2012 para 2013 é responsável por um faturamento de 14,2 bilhões de reais, fazendo com que o país possua o segundo maior mercado mundial. Como algumas famílias chegam a gastar mais de $10 \%$ da renda com seus pets, este mercado se torna atrativo para investimentos. Dentre os diversos fatores que devem ser analisados pelos empreendedores ao investirem neste mercado, alguns estão relacionados com as características do público alvo. Neste sentido, com foco no mercado de alimentação animal, neste estudo verifica-se se: a satisfação com o atendimento prestado e a forma de alimentação de animais domésticos varia de acordo com as características

Doutorando em Administração pela Universidade Nove de Julho - UNINOVE. ivano.adm@ gmail.com

2 Bacharel em Administração pela Universidade Estadual do Oeste do Paraná. filipekvern@ hotmail.com

3 Doutorando emAdministração pela Universidade Nove de Julho-UNINOVE. professorcarvalho@ rocketmail.com

4 Doutorando em Administração pela Universidade Nove de Julho - UNINOVE. renatocintra@ hotmail.com

5 Doutor em Engenharia (PUC/RIO). Professor e Pesquisador do Programa de Pós-graduação em Administração (PPGA) da Universidade Nove de Julho. fernando.antonio.ribeiro.serra@ gmail.com 
dos proprietários? A partir de uma amostra por conglomerados, 385 proprietários de animais domésticos de um município do estado do Paraná - Brasil, responderam um questionário aplicado entre os meses de setembro e outubro de 2013. Os dados foram analisados quantitativamente permitindo a verificação de dois conjuntos de hipóteses. Os resultados indicam que algumas características interferem significantemente na satisfação com atendimento e na forma de alimentação dos animais domésticos.

Palavras-chave: Empreendedorismo. Pet shop. Análise de Mercado.

\section{Abstract}

The market related to pets grows significantly in Brazil. This segment grew at a rate of 16.4\% in 2012 to 2013 is responsible for a turnover of 14.2 billion dollars, making the country has the world's second largest market. As some families come to spend more than $10 \%$ of income with their pets, this market becomes attractive for investment. Among the several factors that should be considered by entrepreneurs to invest in this market, some are related to the target audience characteristics. In this sense, focusing on the animal feed market, in this study we found that the satisfaction with the service provided and the livestock feed profile, vary according to the characteristics of the owners? From a cluster sampling, 385 owners of domestic animals in a city from state of Paraná - Brazil, responded to a questionnaire applied between the months of September and October 2013. The data were analyzed quantitatively allowing checking two sets of hypotheses. The results indicate that some characteristics interfere significantly in satisfaction with care and as livestock feed.

Keywords: Entrepreneurship. Pet shop. Market Analysis.

\section{Introdução}

Nas últimas décadas, o perfil das famílias tem sofrido alteração na sua conformação, há uma redução considerável de casais sem filhos, de famílias cada vez menores e ainda do aumento do número de pessoas que moram sozinhas. Nesse cenário, o animal doméstico, de estimação ou simplesmente pet, está muito presente na vida dos indivíduos e muitas vezes sendo tratados como um membro da família. A imagem do cão preso a uma corrente no quintal da casa, tendo como única e exclusiva função a de guardião está desaparecendo, estando cada vez mais presentes no interior das residências, com o uso de objetos 
como: camas, roupas e brinquedos, possibilitando o aparecimento de um negócio que se apresenta promissor nos próximos anos, as lojas de pequenos animais ou pet shops.

De acordo com dados da Associação Brasileira da Indústria de Produtos para Animais de Estimação - ABINPET (2014), o segmento pet cresce a taxas atraentes. Em 2013, o crescimento foi de 16,4\% em relação ao ano de 2012, sendo que em 2012 o setor de produtos e serviços para pets faturou $\mathrm{R} \$ 14,2$ bilhões, o que elevou o Brasil ao segundo lugar no mercado mundial, atrás apenas para os Estados Unidos. O segmento movimenta mais capital do que setores tradicionais da economia do país, como o da "linha branca", no qual se inserem produtos como geladeiras, máquinas de lavar, fogões, fornos dentre outros, possuindo assim, grande potencialidade para o desenvolvimento local.

As estimativas da ABINPET (2013) já apontavam a existência de 35,7 milhões de cães, 19,8 milhões de gatos, 25 milhões de peixes, 18,5 milhões de aves, além de 2,1 milhões de outros bichos, como roedores, coelhos e tartarugas. No caso dos cães e gatos, o Brasil é considerado o segundo maior plantel do mundo, superado apenas pelos EUA. Esses números apontam o segmento como um promissor setor para se empreender no Brasil, já que a essência do empreendedorismo está na percepção e no aproveitamento dessas oportunidades (FILION, 1999). Contudo, o empreender implica ainda em descobrir dados e informações, preocupando-se com os possíveis resultados das decisões (BOETTKE; COYNE, 2003). Assim, é necessário ter o mais próximo da certeza de o quão promissor é um segmento para então efetuar um investimento (BRUNI, 2010).

Como conhecimentos sobre necessidades, satisfação e deficiências na oferta de produtos e serviços são questões fundamentais antes de empreender em algum setor (DEGEN, 2009), neste artigo, verifica-se se a satisfação com o atendimento prestado e a forma de alimentação de animais domésticos varia de acordo com as características dos proprietários. Para tanto, aplicou-se um questionário 
para 385 proprietários de animais domésticos de um município do estado do Paraná - Brasil, pelo método de amostra por conglomerado. Dessa forma, foi possível testar dois conjuntos de hipóteses de pesquisa: o primeiro relacionado com a satisfação com atendimento e o segundo com a forma de alimentação dos animais.

Esta pesquisa procurou contribuir no campo dos estudos do empreendedorismo e desenvolvimento local e empiricamente para um setor em crescimento sendo de interesse tanto aos empreendedores desta atividade quanto para os usuários.

\section{Empreendedorismo e desenvolvimento local}

A criação de novos negócios é um fator fundamental para o desenvolvimento e criação de riquezas tanto em nível local como regional (VENKATARAMAN, 2004; MATOS; VASCONCELOS, 2013; MENEGHATTI et al., 2014). A função do empreendedorismo é identificar como surgem as oportunidades de negócios para criar algo novo produtos, serviços, mercados, processos e formas de organização das tecnologias existentes (BARON; SHANE, 2007). Para Ferreira et al. (2014), face à incapacidade de dos estados terem soluções, os indivíduos é que são chamados a assumir as responsabilidades.

O empreendedorismo está associado ao progresso econômico, embora esteja ausente da maioria dos modelos econômicos, os empreendedores representam a força motriz do crescimento econômico, por serem responsáveis pela introdução de inovações no mercado (SCHUMPETER, 1982; BARROS; PEREIRA, 2008). A força das empresas que compõem os sistemas produtivos locais é depende das características específicas de seu ambiente imediato, e estas características precisam ser identificadas e analisadas para só então tomar a decisão de empreender ou não em uma região (ARZENI; PELLEGRIN, 1997).

Autores como Dolabela (1999), Dornelas (2008) e Degen (2009) definem o termo "empreendedor" a partir do conceito de origem francesa, 
entrepreneur, que significa "aquele que assume riscos e começa algo novo", baseado na definição schumpeteriana de destruição da ordem econômica pela inovação (SCHUMPETER, 1982). Dessa forma, os empreendedores são detectores de oportunidades no segmento empresarial, sendo aqueles que comumente iniciam um novo negócio, alavancando recursos, impulsionando talentos e ideias que movem a economia nacional e local (BRUNI, 2010).

Passos (2007) cita a pesquisa da Global Entrepreneurship Monitor (GEM), que é um programa de pesquisa de abrangência internacional criado em 1999 e que avalia os níveis de atividade empreendedora nos países inscritos. Para o autor, em 2006, o Brasil mantinha a sétima posição entre os países mais empreendedores dentre os 37 analisados, sendo que, dos 13 milhões de empreendedores investigados, mais de $53,8 \%$ foram motivados por oportunidade.

Ao perceber e aproveitar as oportunidades existentes em um mercado, o empreendedor gera equilíbrio em um ambiente de caos e turbulência (KIRZNER, 1973). Isso ocorre porque essas novas atividades possuem grande potencial de geração de desenvolvimento e valor econômico, ou seja, lucro (BARON; SHANE, 2007). Complementar, o processo empreendedor se inicia na visualização de uma oportunidade e ao longo do tempo se move em uma série de diferentes fases, tais como: o planejamento, a estruturação e o gerenciamento. Os resultados de cada fase são afetados por fatores de nível individual, grupal e social.

Do ponto de vista econômico, Drucker (1987) apresenta uma definição ao conceito de empreendedor baseada no célebre economista clássico francês em Jean-Baptiste Say, no qual atribui ao empreendedor o papel de transferir recursos econômicos de setores de produtividade mais baixa para setores de produtividade mais alta e de maior rendimento, gerando mais eficiência e eficácia à econômica.

Para análise da relação entre empreendedorismo e crescimento econômico, é necessário compreender que o empreendedorismo pode se manifestar de diferentes formas e regimes institucionais, sendo alguns com caráter alternativo e não necessariamente consistentes com 
o desenvolvimento econômico (BOETTKE; COYNE, 2003). De acordo com Schumpeter (1982), há uma demanda de combinações entre empresas e indivíduos capazes de realizar os negócios com resultados efetivos. Essa combinação tem como condicionante o ambiente econômico e sociocultural em que estão imersos, e compreendê-lo é necessário para realizar sua função e impulsionar o desenvolvimento econômico (GOMES, 2011).

Os sistemas locais, como concorrentes, clientes, fornecedores e outros recursos, compõem o hall de conhecimentos necessários ao empreendedor para lhe conferir assertividade na decisão de empreender (ARZENI; PELLEGRIN, 1997). Nesse sentido, Malecki (1993) destaca, ainda, que a identificação de oportunidades de negócios em uma determinada região potencializa as chances de sucesso do novo negócio.

Como o empreendedor possui a capacidade de liderar, inovar, efetuar novas combinações produtivas, tomar iniciativa e guiar o negócio ao resultado, ele se torna fundamental para o alcance do desenvolvimento econômico (SCHUMPETER, 1982). Esse argumento é corroborado por Rosas e Cândido (2008), que destacam a importância do entendimento do negócio e dos fatores que possam contribuir para a promoção do desenvolvimento local, como aproveitar as oportunidades existentes em uma determinada localidade. No intuito de entender melhor as questões relacionadas aos "negócios e oportunidades", na próxima seção esses pontos são abordados no contexto desta pesquisa.

\section{Negócios e oportunidades}

Os resultados oficiais do Serviço Brasileiro de Apoio às Micro e Pequenas Empresas - SEBRAE (2014) sobre micro e pequenas empresas brasileiras apontam que $78 \%$ dos empreendimentos abertos no triênio 2003-2005 permaneceram no mercado. Resultado positivo em relação ao triênio anterior 2000-2002, que teve um índice de permanência de apenas 50,6\% (PASSOS, 2007). De maneira geral, os especialistas brasileiros possuem uma visão positiva em relação às oportunidades 
para criação de novas empresas, ao mesmo tempo, consideram que não é fácil identificar tais oportunidades.

A compreensão de oportunidades demanda a compreensão de fenômenos microeconômicos, e estes orientarão as decisões individuais e de mercado (KIRZNER, 2009). Nesse contexto, mudanças de preços, padrões de resultados, métodos de produção, perfil de consumidores, recursos (incluindo os financeiros, humanos e tecnológicos), dentre outras, definem os padrões de mercado e as oportunidades de negócios. O empreendedor, então, também deve ser o agente com a capacidade de transpor os vazios e gaps existentes no mercado, além de usufruir das vantagens geradas pelas oportunidades (LEIBENSTEIN, 1968). $\mathrm{O}$ indivíduo que empreende também deve ser o agente que detém o ferramental necessário para identificar e explorar novas oportunidades a partir da combinação dos mais diversos recursos (VALE; WILKINSON; AMÂNCIO, 2008).

Baron e Shane (2007) explicam que os setores se diferem em sua estrutura, fazendo com que alguns deles sejam mais receptivos para novas empresas do que outros, e identificam quatro aspectos da estrutura de um setor:

a) capital intensivo: refere-se ao grau de dependência que o processo produtivo de um setor possui em relação ao capital, em vez de mão de obra, sendo necessário o dispêndio de alto capital para obter equipamentos, estabelecer instalações de produção e distribuição antes de gerar receita;

b) economias de escala: em determinados setores as economias de escala existem sempre que o custo de produzir a primeira unidade de algo, for maior do que produzir unidades adicionais, levando um tempo considerável para que novas empresas consigam o mesmo nível de manutenção de custos unitários;

c) concentração: indica que o índice de participação no mercado está em poder de poucas e normalmente das maiores empresas do setor. Novas empresas entrantes devem desafiar a base dos clientes 
das empresas já estabelecidas, com a força e os recursos necessários para tirá-los do negócio;

d) fragmentação: novas empresas possuem melhor desempenho em setores com estes aspectos, pois são compostos de empresas de pequeno e médio porte, minimizando os custos e o risco para estabelecerem seus novos empreendimentos.

Considerando que negócios e oportunidades são explorados e aproveitados a partir da constituição de "empresas", que, por sua vez, demanda conhecimento sobre o "mercado" pleiteado, considera-se cabível uma análise sobre estes dois elementos do empreendedorismo, os quais são apresentados na seção seguinte.

\section{Empresas e mercados}

A empresa é comumente definida pelos economistas como uma unidade básica do sistema econômico, cuja principal função é produzir bens e serviços (SANTOS, 2005). Para conseguir fabricar seus produtos ou oferecer seus serviços, a empresa combina diversos fatores de produção, ou seja, os recursos naturais, o capital e o trabalho necessários. Toda empresa que inicia suas operações deve ter: clareza em seu propósito, consciência de onde quer chegar, quais serão os valores e a estratégia de crescimento (DORNELAS, 2011).

A teorização empresarial, baseada no conceito schumpeteriano, é pautada em decisões, maximização de resultados e geração de equilíbrio como pressuposto de sucesso empresarial (KIRZNER 2009). As empresas são um conglomerado de processos, e um processo, por sua vez, é qualquer atividade ou conjunto de atividades que toma um input, adiciona valor a ele e fornece um output a um cliente específico, assim, a empresa precisa ser vista como um processo cíclico de transformação e de geração de outputs (resultados) e, consequentemente, de valores (GONÇALVES, 2000).

O mercado deve ser analisado iniciando com o ramo setorial de negócios que se pretende atuar e o mercado-alvo ou nicho de mercado 
que se objetiva focar inicialmente dentro deste setor (DORNELAS, 2011). Toda empresa está inserida em um ambiente composto por um conjunto de forças competitivas que determinam o seu nível de retomo ou rentabilidade, sendo que a intensidade dessas forças varia de negócio para negócio (PORTER, 2004). Esse é um ambiente (mercado) que possui mudanças associadas a vários fatores, tais como: desenvolvimento tecnológico, integração de mercados, comportamento de concorrentes, deslocamento da concorrência, redefinição do papel das organizações, além das mudanças no perfil demográfico e nos hábitos dos consumidores, afetam as condições e o desempenho da organização (CAMARGO; DIAS, 2003). Dessa forma, é fundamental identificar e responder as necessidades, entendendo as tendências do mercado (PASSOS, 2007).

Um dos maiores desafios para compreender o mercado que se objetiva explorar é prever as ações dos concorrentes, pois nem sempre eles se comportam de maneiras racionais ou compreensíveis (ZAHRA; NEUBAUM; EL-HAGRASSEY, 2002). Acrescenta-se, ainda, que os concorrentes de um mercado podem ter diferentes formas de competir, considerando aspectos como: tecnologia, hostilidade da concorrência, e estágio do ciclo de vida do setor. É a partir desse conjunto de conceitos e pressupostos que fundamentamos este trabalho e formulamos as hipóteses desta pesquisa.

\section{Formulação das hipóteses de pesquisa}

O empreendedor deve ir além da observação e conhecimento do negócio: deve entender os desejos e necessidades dos clientes do negócio, identificar necessidades não atendidas, detectar deficiências de atendimento e atender melhor essa lacuna e compreender as possíveis mudanças nos comportamentos (DEGEN, 2009).

Para responder ao questionamento da pesquisa, foram formuladas e testadas doze hipóteses divididas em dois conjuntos: o primeiro relacionado à satisfação com o atendimento e o segundo pautado na forma de alimentação dos animais de estimação. 
O primeiro ponto - "atendimento" - pode ser um grande diferencial competitivo para uma empresa, mas também pode destruir um relacionamento comercial quando for mal desenvolvido (GRÖNROOS, 2004). O atendimento é extremamente valorizado pelos clientes de pet shops, que esperam por um atendimento especializado em todos os estágios - da recepção até o pós-venda (LIMA et al., 2013). Nesse sentido, o bom atendimento é uma das melhores formas de um pet shop conseguir diferenciar-se da concorrência (MOURA et al., 2011). Porém, o nível de atendimento prestado por empresas do comércio nacional ainda é muito baixo, e mais de $65 \%$ das perdas de clientes é ocasionado pelo mau atendimento (DINIZ; FUERTH, 2009).

O conhecimento sobre as características dos clientes é um ponto fundamental para que uma empresa possa adequar o atendimento às necessidades e expectativas específicas de seus clientes. Nesse sentido, entende-se que questões relacionadas com: características demográficas; características de consumo; e características de criação de pequenos animais são fatores que interferem significativamente no nível de satisfação do atendimento. Dessa forma, o primeiro conjunto de hipóteses de pesquisa que formulamos se relaciona com a influência dessas características sobre o nível de satisfação com o atendimento, sendo:

Hipótese 1a. Consumidores de diferentes gêneros, possuem diferentes níveis de satisfação com o atendimento oferecido pelos pet shops.

Hipótese 1b. Consumidores com diferentes faixas etárias possuem diferentes níveis de satisfação com o atendimento oferecido pelos pet shops.

Hipótese 1c. Consumidores de diferentes tipos de estabelecimentos possuem diferentes níveis de satisfação com o atendimento oferecido.

Hipótese 1d. Consumidores que optam pela compra por delivery possuem diferentes níveis de satisfação com o atendimento dos pet shops do que os que não compram pelo sistema. 
Hipótese 1e. Proprietários com diferentes perfis de criação possuem diferentes níveis de satisfação com o atendimento oferecido pelos pet shops.

Hipótese 1f. Proprietários de diferentes animais possuem diferentes níveis de satisfação com o atendimento oferecido pelos pet shops.

As indústrias do segmento estão investindo maciçamente no desenvolvimento de produtos relacionados à alimentação animal, e que atendam todas as necessidades nutricionais das mais diversas espécies pets. Porém, no país, ainda existe um grande percentual de pets consumindo dietas caseiras (CARCIOFI, 2007).

Isso abre uma grande oportunidade para as empresas de fornecimento de rações e demais complementos alimentares, já que cada vez mais os proprietários se conscientizam da necessidade de fornecer aos seus animais de estimação uma alimentação adequada e balanceada (SAAD; FRANÇA, 2010). Como as características dos proprietários de animais domésticos podem direcionar também para diferentes formas de criação dos animais, entendemos que diferentes características dos proprietários também interfiram na forma de alimentação dos pets. Nesse sentido, apresenta-se o segundo conjunto de hipóteses:

Hipótese 2a. Consumidores de diferentes gêneros possuem diferentes formas de alimentação de seus animais de estimação.

Hipótese $\mathbf{2 b}$. Consumidores com diferentes faixas etárias possuem diferentes formas de alimentação de seus animais de estimação.

Hipótese 2c. Consumidores de diferentes tipos de estabelecimentos possuem diferentes formas de alimentação de seus animais de estimação.

Hipótese 2d. Consumidores que optam pela compra por delivery possuem diferentes formas de alimentação de seus animais de estimação.

Hipótese 2e. Proprietários com diferentes perfis de criação possuem diferentes formas de alimentação de seus animais de estimação.

Hipótese 2f. Proprietários de diferentes animais possuem diferentes formas de alimentação de seus animais de estimação. 


\section{Método}

Para testar as hipóteses formuladas as variáveis dependentes foram: o nível de satisfação com o atendimento prestado pelos pet shops e a forma de alimentação dos animais de estimação. As variáveis independentes foram as características dos proprietários de animais domésticos. Das seis variáveis que compõem este último construto, duas delas são relacionadas com características pessoais "gênero e idade", duas relativas às características de consumo "tipo de estabelecimento e opção por entrega (delivery)", e outras duas referentes às características de criação "perfil de criação e tipo de animal”, conforme Figura 1.

Figura 1: Variáveis de pesquisa

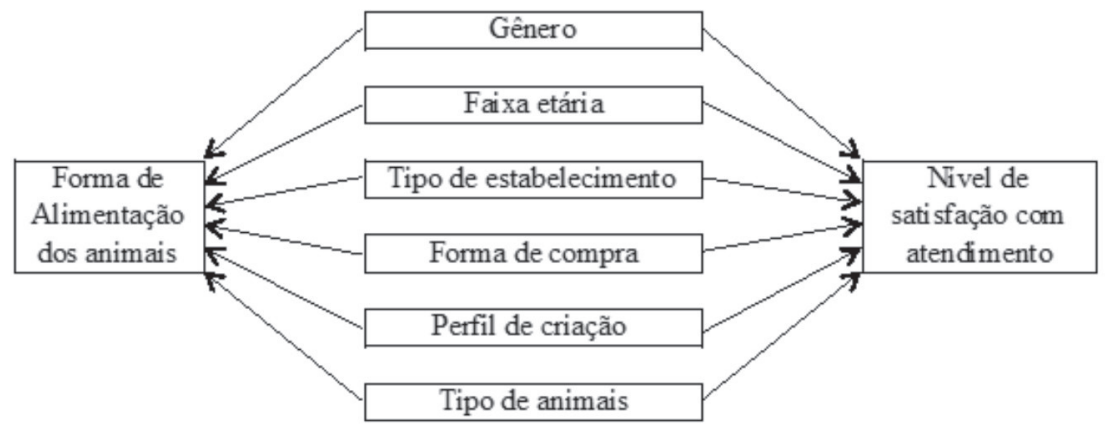

Fonte: Elaborado pelos autores (2014).

O instrumento de pesquisa foi um questionário com escala de cinco pontos, sendo: 1 - nunca; 2 - raramente, 3 - as vezes; 4 - quase sempre; 5 - sempre, que foi aplicado entre setembro e outubro de 2013. Foram utilizadas questões dicotômicas e de múltipla escolha para mensurar as características dos respondentes. Para assegurar um completo entendimento do questionário pelos respondentes, realizamos ainda um pré-teste por meio da técnica de focus group com sete membros pré-selecionados, e que se enquadravam às características da amostra, conforme aborda Galego e Gomes (2005). 
A amostra foi calculada com base na população total de residentes do município pesquisado, situado no estado do Paraná e com uma população estimada pelo Instituto Brasileiro de Geografia e Estatística IBGE (2013) de 286.205 habitantes em 2010. A pesquisa contou com 385 respondentes, sendo todos proprietários de algum tipo de pet. Adotamos a amostragem por conglomerados, conforme destacam Barata et al. (2005). Para a formação de cada conglomerado empregamos o modelo adotado pela Secretaria de Planejamento e Urbanismo - SEPLAN (2013) do município pesquisado. A divisão contempla sete unidades: Centro, Centro-Sul, Centro-Norte, Leste, Norte, Sul e Oeste; assim, os sete conglomerados contaram com 55 respondentes cada.

Os dados foram analisados de forma quantitativa utilizando os testes $t$-Student e Anovaone-way (um fator), seguido do teste post hoc HSD Turkey. O primeiro teste ( $t$-Student) serve para verificar se as médias de duas populações são ou não significantemente diferentes. Já a Anova one-way indica se três ou mais amostras possuem tais diferenças. Quando as diferenças são significativas em um conjunto de variáveis analisadas, o teste post hoc HSD Turkey tem o poder de identificar por meio de uma análise múltipla das médias em que as diferenças se concentram (HAIR et al., 2009; MARÔCO, 2010).

Nessa fase de análise, foram observados os valores de VIF Variance Inflation Factor, que segundo Hair et al. (2009) podem indicar a existência de alta multicolinearidade entre as variáveis analisadas. Isto não foi observado, já que, o maior valor encontrado entre as variáveis independentes foi (VIF =1,140), o que denota a existência de uma baixa colinearidade. Para a análise, adotou-se um nível de significância de 0,05 , optando pela apresentação dos resultados por meio de gráficos seguidos de análises descritivas.

\section{Resultados}

Do total de 385 respondentes da pesquisa, quase $70 \%$ são proprietários de cães, seguido de gatos (15\%) e aves domésticas $(14 \%)$. Os demais representam animais como peixes ornamentais e 
animais exóticos (1\%). As marcas citadas como as mais utilizadas para alimentação de cães foram: Pedigree, Dog Show, Royal Canin e Alpo. Para gatos foram: Whiskas, Friskies, Premier e Royal Canin. Já para aves as mais citadas foram: Girasol, Alpiste e Alcon. Visando testar as hipóteses formuladas, inicialmente observamos as médias e desvios padrão das variáveis: satisfação com o atendimento oferecido e frequência de alimentação dos pets com ração animal, os dados são apresentados na Tabela 1.

Tabela 1: Médias das variáveis dependentes de pesquisa

\begin{tabular}{lccccc}
\hline Item & N & Mínimo & Máximo & Média & $\begin{array}{c}\text { Desvio } \\
\text { Padrão }\end{array}$ \\
Satisfação com o atendimento oferecido & 385 & 1 & 5 & 4,69 & 0,784 \\
Frequência da alimentação com ração & 385 & 1 & 5 & 4,70 & 0,693 \\
\hline
\end{tabular}

Fonte: Elaborado pelos autores (2014)

Observou-se que as médias das duas variáveis são muito próximas $(M=4,69$; e $M=4,70)$, valores relativamente alto em relação à escala de 5 pontos utilizada. Na sequência, também foram verificadas as médias e desvios dessas variáveis em diferentes grupos de respondentes, que foram separados por: gênero, faixa etária, tipo de estabelecimento em que adquire os produtos (se pet shop ou outro estabelecimento), se opta ou não em compra por delivery, se cria o seu pet em ambiente interno ou externo à residência, e por tipo de pet (ave, cão, gato e mais de um tipo/espécie).

Os resultados dos testes $t$-Student para duas amostras, e da Anovaone-way (um fator) para três ou mais amostras, são apresentados a seguir. Observam-se inicialmente as diferenças entre as médias da variável satisfação com o atendimento oferecido, conforme Figura 2. 
Figura 2: Medida de satisfação com os serviços prestadoş
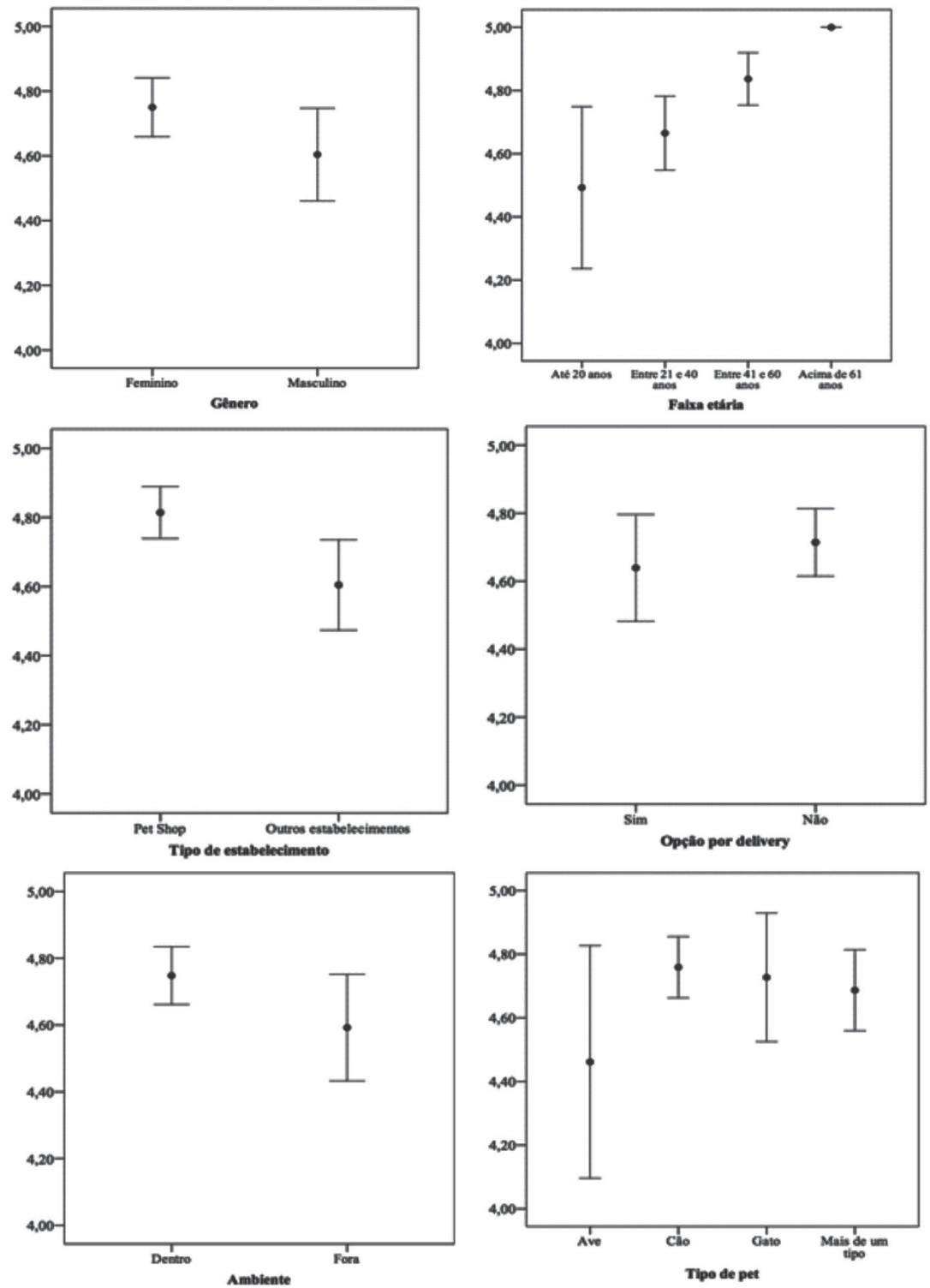

* Diferenças significantes ao nível de 0,05.

Fonte: Elaborado pelos autores (2014) 
Com relação à satisfação com os serviços prestados no município, não foi notada diferença na satisfação entre os gêneros $(t=1,170 ; p=$ $0,09)$. Quanto à satisfação dentro das quatro faixas etárias pesquisadas, verificou-se a existência de diferenças significantes no grupo ( $F=3,397$; $p=0,018)$, por meio do teste post hoc HSD Turkey, identificando-se que a diferença se concentra na relação dos grupos de respondentes de até 20 anos e entre 41 a 60 anos (Diferença $M=0,344 ; p=0,023$ ).

O nível de satisfação foi estatisticamente idêntico entre os respondentes que optam por compra em lojas especializadas (pet shops) e outros tipos de lojas, como: mercados, supermercados e outros $(t=-1,617 ; p=0,117)$. A opção por delivery também não interferiu na satisfação dos respondentes $(t=1,785 ; p=0,75)$. $O$ fato de o pet ser criado dentro ou fora de casa não possui relação com a satisfação do atendimento $(t=1,848 ; p=0,065)$. $O$ tipo de pet também não possui relação com o nível de satisfação ( $F=1,383 ; p=0,248)$.

Diante desses resultados, só é possível não rejeitar a hipótese 1b, tendo em vista que os respondentes mais novos (menos de 20 anos) possuem menor nível de satisfação do que os respondentes mais velhos (entre 41 e 60 anos). Foram rejeitadas as cinco demais hipóteses desse grupo, como segue:

Hipótese 1a. Consumidores de diferentes gêneros, possuem diferentes níveis de satisfação com o atendimento oferecido pelos pet shops (Rejeitada).

Hipótese 1b. Consumidores com diferentes faixas etárias possuem diferentes níveis de satisfação com o atendimento oferecido pelos pet shops (Não Rejeitada).

Hipótese 1c. Consumidores de diferentes tipos de estabelecimentos possuem diferentes níveis de satisfação com o atendimento oferecido (Rejeitada).

Hipótese 1d. Consumidores que optam pela compra por delivery possuem diferentes níveis de satisfação com o atendimento dos pet shops do que os que não compram pelo sistema (Rejeitada). 
Hipótese 1e. Proprietários com diferentes perfis de criação possuem diferentes níveis de satisfação com o atendimento oferecido pelos pet shops (Rejeitada).

Hipótese 1f. Proprietários de diferentes animais possuem diferentes níveis de satisfação com o atendimento oferecido pelos pet shops (Rejeitada).

Na sequência, foi testado o segundo conjunto de variáveis e novamente recorreu-se aos testes $t$-Student e Anovaone-way, da mesma forma que a análise do primeiro conjunto de variáveis. Na Figura 3, apresentam-se os resultados que são argumentados em seguida. 
Figura 3: Frequência de alimentação dos pets com ração animal
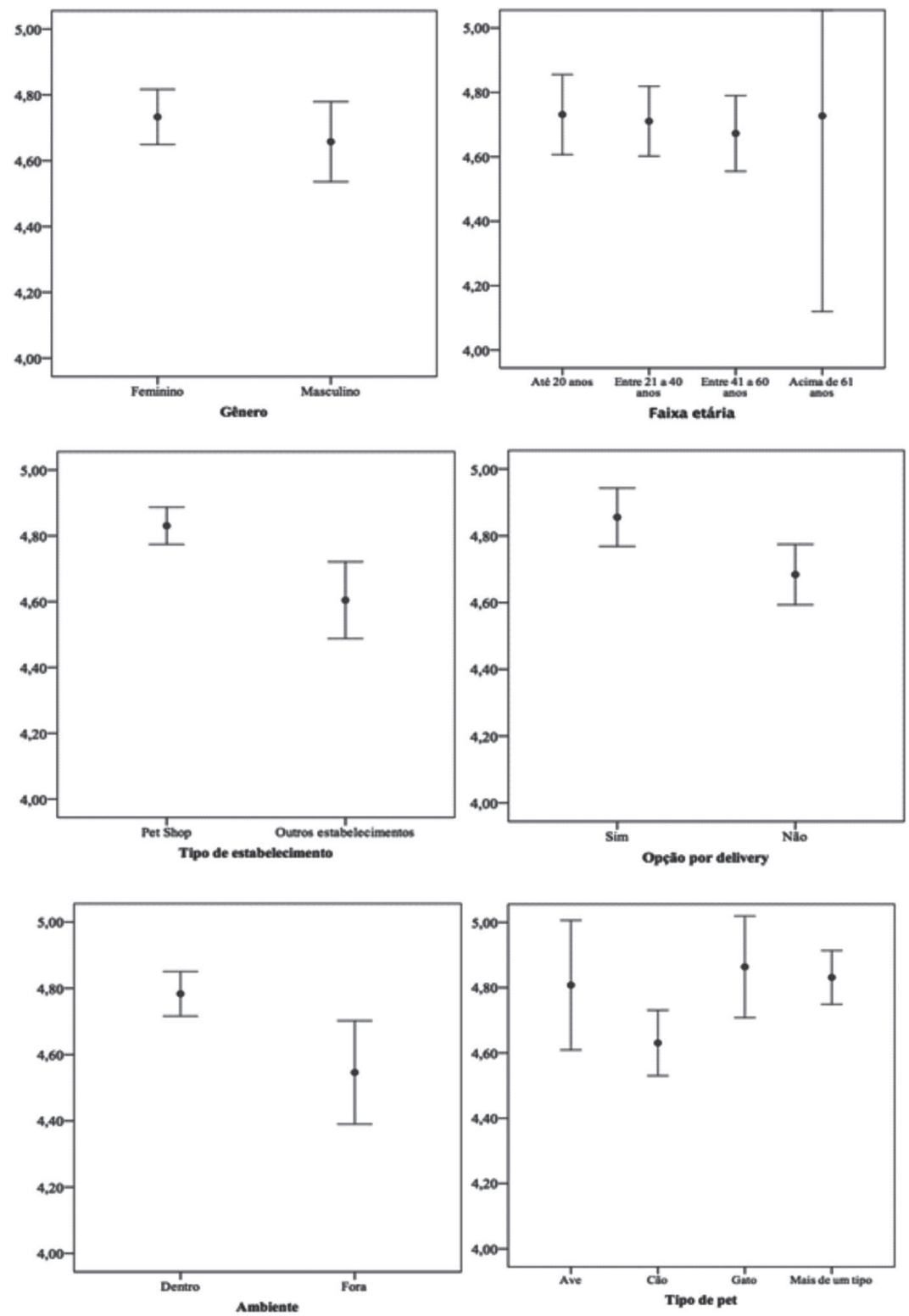

* Diferenças significantes ao nível de 0,05.

Fonte: Elaborado pelos autores (2014) 
Na Figura 3, observam-se as frequências com que os proprietários alimentam seus pets com ração animal. Não foram identificadas diferenças estatisticamente significantes entre os grupos formados por homens e mulheres $(t=1,039 ; p=0,299)$. O mesmo ocorreu entre as diferentes faixas etárias pesquisadas $(F=0,119 ; p=0,949)$.

O grupo de respondentes que compra em pet shops possui médias de alimentação com ração superior aos clientes de lojas convencionais, como mercados, supermercados e outros $(t=3,870 ; \mathrm{p}$ $=0,000)$. A diferença também ocorreu entre os grupos que optam por comprar presencialmente e aqueles que preferem o delivery. Os que compram pelo sistema de delivery possuem médias de alimentação com ração animal mais elevadas daqueles que adquirem presencialmente $(t$ $=2,248 ; p=0,025)$.

Os pets que são criados dentro de casa também possuem um grau de alimentação com ração superior aos criados fora de casa $(t=$ $3,212 ; p=0,001)$. Já entre os grupos de proprietários de diferentes pets, não houve diferenças no grau de alimentação com ração animal ( $F=$ 2,$450 ; p=0,063$ ). Esses resultados nos fornecem suporte para a não rejeição de três das seis hipóteses desse segundo conjunto, sendo:

Hipótese 2a. Consumidores de diferentes gêneros possuem diferentes formas de alimentação de seus animais de estimação (Rejeitada).

Hipótese 2b. Consumidores com diferentes faixas etárias possuem diferentes formas de alimentação de seus animais de estimação (Rejeitada).

Hipótese 2c. Consumidores de diferentes tipos de estabelecimentos possuem diferentes formas de alimentação de seus animais de estimação (Não rejeitada).

Hipótese 2d. Consumidores que optam pela compra por delivery possuem diferentes formas de alimentação de seus animais de estimação (Não rejeitada).

Hipótese 2e. Proprietários com diferentes perfis de criação possuem diferentes formas de alimentação de seus animais de estimação (Não rejeitada). 
Hipótese 2f. Proprietários de diferentes animais possuem diferentesformas de alimentação de seus animais de estimação (Rejeitada).

\section{Discussão}

Os resultados apontam que, embora haja diferenças no nível de satisfação entre as faixas etárias pesquisadas (entre o grupo de até 20 anos e o grupo entre 41 e 60 anos), de forma geral, houve um grau elevado de satisfação com o atendimento oferecido por pet shops do município. De acordo com Mello e Vieira (2008), as empresas brasileiras, inclusive as de pequeno porte, já possuem um direcionamento no sentido de melhoria do processo de atendimento ao cliente. Dessa forma, elas buscam desenvolver e manter os relacionamentos em médio e longo prazo.

Verificou-se que alguns grupos se diferem na forma de alimentação dos pets, os respondentes que adquirem produtos em pet shopsalimentam seus animais de estimação com ração em um nível mais elevado dos que os que compram em outros tipos de estabelecimentos. Destaca-se que a indústria do segmento possui uma variedade de mais de cinco mil produtos, sendo uma fatia considerável relacionada à alimentação animal (MOURA et al., 2011). Assim, as lojas especializadas tendem a possuir um mix mais diversificado de produtos, sendo a primeira opção para estes clientes.

Os resultados apontam, ainda, que proprietários que alimentam seus animais de estimação com ração necessitam que o suprimento seja ágil, e com a escassez de tempo no dia a dia, uma opção é o delivery, que ganhou muitos adeptos por meio da entrega de pizzas e hoje abrange uma grande diversidade de segmentos. Essas empresas do segmento pet estão buscando a inovação em serviços, e um desses diferenciais é o serviço de atendimento a domicilio (LIMA et al., 2013).

Também foi observado que os respondentes que criam seus pets dentro de casa também são os que utilizam a ração como principal fonte 
de alimentação animal. Isso converge com os resultados do estudo de Lima et al. (2013), os quais apontam que muitas vezes os animais de estimação são considerados membros da família e recebem tratamento como tal. Eles convivem no mesmo ambiente de seus donos, que sempre procuram pelos melhores produtos e serviços disponíveis, com intenção de melhorar a qualidade de vida dos seus animais.

O segmento analisado (pet shop) possui um grande potencial de desenvolvimento, merecendo uma atenção especial de empresários, empreendedores e pesquisadores. Nesse sentido, buscou-se por meio deste estudo analisar algumas variáveis que foram julgadas essenciais para o segmento, e especificamente às relacionadas ao de alimentação animal.

\section{Considerações finais}

Neste estudo, analisou-se o segmento pet em um município do estado do Paraná, a partir de duas perspectivas: o nível de satisfação com o atendimento prestado pelos pet shops e a forma de alimentação dos animais. Os resultados indicam que: a satisfação com o atendimento e a existência de diferentes formas de alimentação animal são aspectos a serem observados pelos empreendedores potenciais que tenham pretensão de explorar este segmento. Dessa forma, ao considerar o segmento pet como um fator contribuinte para o desenvolvimento local é necessário a compreensão destas condicionantes para sua viabilidade.

Destaca-se que o artigo se limita a análise de proprietários de pequenos animais de um único município, não permitindo assim generalizações de resultados, pelo menos à luz da teoria. O artigo também se limitou a análise de características demográficas; características de consumo; e características de criação de pequenos animais. Assim, novos estudos neste campo, podem ampliar o entendimento verificando ainda a possível influência de características culturais sobre a satisfação com o atendimento e a forma de alimentação dos animais. 


\section{Referências}

ARZENI, S.; PELLEGRIN, J. Entrepreneurship and local development. OECD Observer, França, v. 23, n. 204, p. 27-29, Feb./ Mar.1997.

ASSOCIAÇÃO BRASILEIRA DA INDÚSTRIA DE PRODUTOS PARA ANIMAIS DE ESTIMAÇÃO - ABINPET. Dados consolidados do mercado pet referentes a 2013.

Disponível em: <http://abinpet.org.br/imprensa/noticias/abinpetdivulgadados-mercado-pet-2013>. Acesso em: 12 dez. 2014.

. História. Disponível em: <http://abinpet.org.br/sobre-a-abinpet/ historia>. Acesso em: 15 maio 2013.

BARATA, R. B.; MORAES, J. C.; ANTONIO, P. R. A.; DOMINGUES, M. Inquérito de cobertura vacinal: avaliação empírica da técnica de amostragem por conglomerados proposta pela Organização Mundial da Saúde. Revista Panamericana de Salud Publica, Washington, DC, v. 17, n. 3, p. 184-190, mar. 2005.

BARON, R. A.; SHANE, S. A. Empreendedorismo: uma visão do processo. São Paulo: Cengage Learning, 2007.

BARROS, A. A.; PEREIRA, C. M. M. A. Empreendedorismo e crescimento econômico: uma Análise Empírica. Revista de Administração Contemporânea, Curitiba, v. 12, n. 4, p. 975-993, out./dez.2008.

BOETTKE, P. J.; COYNE, C. J. Entrepreneurship and development: cause or consequence? Advances in Austrian Economics, Washington v. 6, p. 67-87, sep. 2003.

BRUNI, A. L. Manual do empreendedor: conceitos, casos e desafios. Universidade Federal da Bahia / Escola de Administração / Empresa Júnior. Salvador: Infinita Editora, 2010.

CAMARGOS, M. A.; DIAS, A. T. Estratégia, administração estratégica e estratégia corporativa: uma síntese teórica. Caderno de Pesquisas em Administração, São Paulo, v. 10, n. 1, p. 27-39, jan./mar.2003. 
CARCIOFI, A. C. Métodos para estudo das respostas metabólicas de cães e gatos a diferentes alimentos. Revista Brasileira de Zootecnia, Viçosa, Minas Gerais, v. 36, p. 235-249, jul. 2007.

DEGEN, R. J. O Empreendedor como Opção de Carreira. São Paulo: Pearson Prentice Hall, 2009.

DINIZ, T. P. R.; FUERTH, L. R. Qualidade no atendimento no setor de serviços: a era do cliente. Revista Caderno de Administração, Maringá, v. 1, n. 3, jun., 2009.

DOLABELA, F. Oficina do empreendedor. São Paulo: Cultura Editores Associados, 1999.

DORNELAS, J. C. A. Empreendedorismo: transformando ideias em negócios. 3. ed. Rio de Janeiro: Elsevier, 2008.

- Plano de Negócios: seu guia definitivo. Rio de Janeiro: Elsevier, 2011.

DRUCKER, P. F. Inovação e espírito empreendedor. prática e princípios. São Paulo: Pioneira, 1987.

FERREIRA, M. P. et. al. Pesquisa em empreendedorismo no principal periódico internacional: um estudo bibliométrico das publicações no journal of business venturing entre 1987 e 2010. Revista de Empreendedorismo e Gestão de Pequenas Empresas, Curitiba, v. 3, n. 1, p. 56-83, 2014.

FILION, L. J. Empreendedorismo: empreendedores e proprietáriosgerentes de pequenos negócios. Revista de Administração, São Paulo, v. 34, n. 2, p. 5-28, abr./ jun. 1999.

GALEGO, C.; GOMES, A. A. Emancipação, ruptura e inovação: o "focus group" como instrumento de investigação. Revista Lusófona de Educação, Campo Grande, v. 5, n. 5, p. 173-184, jan./jun. 2005.

GOMES, A. F. O empreendedorismo como uma alavanca para o desenvolvimento local. REA-Revista Eletrônica de Administração, Franca-São Paulo, v. 4, n. 2, jul./dez. 2005. 
GONÇALVES, J. E. L. As Empresas são grandes coleções de processos. Revista de Administração de Empresas, São Paulo, v. 40, n. 1, p. 6-19, jan./mar.2000.

GRÖNROOS, C. The relationship marketing process: communication, interaction, dialogue, value. The Journal of Business \& Industrial Marketing, [S.I.], v. 19, n. 2, p. 99-113, mar. 2004.

HAIR, J. F. et. al. Análise multivariada de dados. 6a. ed. Porto Alegre: Bookman, 2009.

INSTITUTO BRASILEIRO DE GEOGRAFIA E ESTATÍSTICA (IBGE). Censo 2010. Brasília. Disponível em: <http://www.ibge.gov.br/cidadesat/ painel/painel. php?codmun=410480>. Acesso em: 31 abr. 2013.

KIRZNER, I. M. Competition and entrepreneurship. Chicago: Chicago University Press, 1973.

. The alert and creative entrepreneur: a clarification. Small Business Economics, NY, v. 32, n. 2, p. 145-152, Feb. 2009.

LEIBENSTEIN, H. Entrepreneur and development. The American Economic Review, Pittsburgh, PA v. 58, n. 2, p. 72-84, 1968.

LIMA, B. R. et. al. A. Inovação no mercado de pet shops. Revista de Administração e Inovação, São Paulo, v. 10 , n.1, p. 0626 , Jan./Mar. 2013.

MARÔCO, J. Análise estatística com a utilização do SPSS. Pero Pinheiro: Report Number, 2011.

MALECKI, E. J. Entrepreneurship in regional and local development. International regional science review, Philadelphia, PA, v. 16, n. 1-2, p. 119-153, Dec. 1993.

MATOS, P.; VASCONCELOS, A. Análise de causalidade da mortalidade das pequenas empresas no Brasil. Revista Ciências Administrativas, Fortaleza, v. 19, n. 1, p. 13-34, jan./jun. 2013. 
MELLO, C. M.; VIEIRA, F. G. D. Marketing de relacionamento: um estudo empírico em micro e pequenas empresas do comércio varejista de Campo Mourão/PR. Perspectivas Contemporâneas, Campo Mourão, PR, v. 3, n. 1, p. 109-130, jan./jul. 2008.

MENEGHATTI, M. R. et.al. A gestão do empreendedorismo no meio rural familiar e relatos da situação atual no munícipio de Diamante do Oeste no Estado do Paraná. Revista Sodebras, Paraná, v. 9, n.100, p. 154-157, abr. 2014.

MOURA, L. R. C. et. al. Caso para ensino: estudos sobre o comportamento do consumidor. Pensamento Contemporâneo em Administração, Niterói, v. 5, n. 3, p. 97-114, set./dez. 2011.

ASSOS, A. Inteligência competitiva para pequenas e médias empresas: como superar a concorrência e desenvolver um plano de marketing para sua empresa. São Paulo: LCTE Editora, 2007.

PORTER, M., E. Estratégia competitiva: técnicas para análise da indústria e da concorrência. Elsevier: São Paulo, 2004.

ROSAS, I. A. G.; CÂNDIDO, G. A. Capital social como instrumento para viabilização do desenvolvimento regional: estudo de caso no Cariri Paraibano. Revista Brasileira de Gestão e Desenvolvimento Regional, Taubaté-SP, v. 4, n. 2, p. 58-80, maio/ago.2008.

SAAD, F. M. O. B.; FRANÇA, J. Alimentação natural para cães e gatos. Revista Brasileira de Zootecnia, Viçosa, MG, v. 39, (supl. especial) p. 52-59, Jul. 2010.

SANTOS, S. A. et.al. Empreendedorismo de base tecnológica: evolução e trajetória. Maringá: Unicorpore, 2005.

SCHUMPETER, J. A. Teoria do desenvolvimento econômico: uma investigação sobre lucros, capital, crédito, juro e o ciclo econômico. São Paulo: Abril Cultural, 1982.

SECRETARIA DE PLANEJAMENTO E URBANISMO - SEPLAN. Mapas. Cascavel - PR. Disponível em: <http://www.cascavel.pr.gov.br/ secretarias/seplan/index.php>. Acesso em: 31 maio 2013. 
SERVIÇO BRASILEIRO DE APOIO ÀS MICRO E PEQUENAS EMPRESAS - SEBRAE. Fatores condicionantes e taxas de mortalidade das MPE nos estados: estudos e pesquisas. Disponível em: <http://201.2.114.147/bds/BDS.nsf/8F5BDE79736CB99483257447 006CBAD3/\$File/NT00037936.pdf>. Acesso em: 10 dez. 2014.

VALE, G. V.; WILKINSON, J.; AMÂNCIO, R. Empreendedorismo, inovação e redes: uma nova abordagem. RAE-eletrônica, São Paulo, v. 7 n. 1, p. 1-17, Jan./Jun.2008.

VENKATARAMAN, S. Regional transformation through technological entrepreneurship. Journal of Business Venturing, Charlottesville, U.S., v. 19, n. 1, p. 153-167, jan. 2004.

ZAHRA, S. A.; NEUBAUM, D. O.; EL-HAGRASSEY, G. M. Competitive analysis and new venture performance: understanding the impact of strategic uncertainty and venture origin. Entrepreneurship Theory and Practice, Waco, TX, v. 27, n. 1, p. 1-28, sep. 2002.

Artigo recebido em: 02/04/2015

Aprovado em: 24/06/2015 